users. Drug use by young women is of particular concern and may lead to sexual health morbidity. We believe this group is currently under-recognised and opportunities for risk reduction are being missed.

\section{P096 CONCORDANCE OF CHLAMYDIA INFECTIONS OF THE RECTUM AND URETHRA IN SAME-SEX MALE PARTNERSHIPS: A CROSS-SECTIONAL ANALYSIS}

${ }^{1,2}$ Vincent Cornelisse* ${ }^{3}$ Christopher Sherman, ${ }^{1,4}$ Lei Zhang, ${ }^{1,2}$ Marcus Chen ${ }^{1,2}$ Catriona Bradshaw, ${ }^{1,2}$ Clare Bellhouse, ${ }^{1,2}$ Christopher Fairley, ${ }^{1,2}$ Eric Chow. ${ }^{1}$ Melbourne Sexual Health Centre, Melbourne, Australia; ${ }^{2}$ Monash University, Melbourne, Australia; ${ }^{3}$ University of Melbourne, Melbourne, Australia; ${ }^{4}$ The Kirby Institute, Sydney, Australia

10.1136/sextrans-2016-052718.150

\section{Background}

Sexual health services should ask all high risk attenders about drug and alcohol use. However, the impact of drug and alcohol use on STI epidemiology remains uncertain.

Aims To audit drug and alcohol history taking after introduction of a screening tool and to describe the patterns of use and associations with STI diagnoses.

Methods An anonymised database of all clients attending in 2015 was constructed including basic demographics, reported drug and alcohol history, HIV status and STI diagnoses.

Results 48,654 clients were seen in 2015. 26,429 (54\%) were asked about drug and/or alcohol use at least once. Use of any drug or excess alcohol was reported by $16 \%$ and was associated with higher rates of STIs (24 vs $10 \%, \mathrm{p}<0.001)$. Amongst MSM, 62\% had a drug and/or alcohol history taken, compared with $47 \%$ and $55 \%$ in heterosexual men (MSW) and women, respectively $(\mathrm{p}<0.0001)$. STIs diagnoses were significantly higher in drug users compared to non-users (27 vs 11\%), but were not different comparing alcohol excess vs no excess (14 vs 13\%). STI diagnoses were significantly higher in drug users compared to non-users in all sub-groups - MSM (41 vs 20\%) MSW ( 26 vs $18 \%$ ) women $(12$ vs $7 \%$ ) - all p $<0.0001$.

Conclusions The audit showed room for improvement in history taking. Chemsex drugs are associated with the highest risk of STIs. This relationship might not be causal. Party drug use was associated with some STIs. The audit supports drug and alcohol histories for all MSM as well as heterosexual men and women attending with STIs.

\section{P097 ARE PATIENTS IN RURAL COMMUNITIES INTERESTED IN ONLINE SEXUAL HEALTH SERVICES?}

${ }^{1}$ Amy Pearce ${ }^{*}$, ${ }^{2}$ Rachael Penrose, ${ }^{1}$ Joanne Palmer, ${ }^{1}$ Thomas Perrin, ${ }^{1}$ Frances Keane. ${ }^{1}$ Royal Cornwall Hospital, Truro, UK; ${ }^{2}$ Plymouth College of Medicine and Dentistry, Plymouth, UK

\subsection{6/sextrans-2016-052718.151}

Background/introduction People do not attend Genitourinary Medicine (GUM) services for reasons including cultural beliefs and stigma. In Cornwall geographical isolation, poor transport and local Council budgetary cuts to peripheral clinics also limit access.

$\operatorname{Aim}(\mathrm{s}) /$ objectives To ascertain whether patients would use online services to book appointments and/or order home testing kits.

Methods An anonymised questionnaire survey of GUM patients. Data was recorded into an Excel spreadsheet and analysed using SPSS.

Results 248 questionnaires were returned from women(59.7\%) and men(40.3\%) aged $13-72$ years. 154 (62.3\%) were previous

Abstract P096 Table 1 Association of reported drug and alcohol use and STI diagnosis in 2015

\begin{tabular}{|c|c|c|c|c|c|c|c|}
\hline & & $\begin{array}{l}{ }^{1} \text { Chems Yes, \% } \\
N=26,429 \text { asked }\end{array}$ & ${ }^{4} p$-value & $\begin{array}{l}{ }^{2} \text { Party Yes, } \% \\
N=26,429 \text { asked }\end{array}$ & ${ }^{4} p$-value & $\begin{array}{l}{ }^{3} \text { Alcohol excess, } \% \\
N=20,406 \text { asked }\end{array}$ & ${ }^{4} p$-value \\
\hline \multirow[t]{2}{*}{ Total } & & $4.4 \%$ & & $12 \%$ & & $6 \% n=1225$ & \\
\hline & & $\mathrm{n}=1046$ & & $\mathrm{n}=2891$ & & & \\
\hline Gender/ & MSM & 16.5 & $<0.0001$ & 15.9 & $<0.0001$ & 8.7 & $<0.0001$ \\
\hline \multirow[t]{2}{*}{ Sexual orientation (MSW-heterosexual men) } & MSW & 0.9 & & 18.2 & & 9.1 & \\
\hline & Women & 0.3 & & 7.1 & & 3.9 & \\
\hline \multirow[t]{2}{*}{ New STI this year } & Yes & 17.0 & $<0.0001$ & 19.6 & $<0.0001$ & 6.6 & 0.156 \\
\hline & No & 2.4 & & 10.9 & & 5.9 & \\
\hline \multirow[t]{2}{*}{ Chlamydia } & Yes & 14.0 & $<0.0001$ & 19.1 & 0.435 & 7.1 & 0.257 \\
\hline & No & 20.6 & & 20.2 & & 6.0 & \\
\hline \multirow[t]{2}{*}{ Gonorrhoea } & Yes & 33.2 & $<0.0001$ & 23.8 & $<0.0001$ & 6.8 & 0.753 \\
\hline & No & 7.8 & & 17.2 & & 6.5 & \\
\hline \multirow[t]{2}{*}{ Syphilis } & Yes & 40.1 & $<0.0001$ & 21.7 & 0.320 & 4.7 & 0.191 \\
\hline & No & 14.5 & & 19.3 & & 6.8 & \\
\hline \multirow[t]{2}{*}{ HSV } & Yes & 8.0 & $<0.0001$ & 17.4 & 0.190 & 5.3 & 0.205 \\
\hline & No & 18.6 & & 20.0 & & 6.9 & \\
\hline \multirow[t]{2}{*}{ Hepatitis B } & Yes & 17.1 & $<0.006$ & 9.7 & 0.252 & 6.7 & 1.000 \\
\hline & No & 0 & & 19.7 & & 6.6 & \\
\hline \multirow[t]{2}{*}{ Hepatitis C } & Yes & 65.7 & $<0.0001$ & 45.7 & $<0.0001$ & 0 & 0.166 \\
\hline & No & 16.4 & & 19.3 & & 6.7 & \\
\hline
\end{tabular}

${ }^{1}$ "Chemsex drugs" (mephedrone, gamma-Hydroxybutyric acid, methamphetamine)

2"Party drugs" (cannabis, ecstasy/MDMA, cocaine, ketamine)

${ }^{3}$ Excess alcohol use was $>14$ units for women and $>21$ units for men.

${ }^{4} \mathrm{p}$-values calculated using Chi squared or Fisher exact test as appropriate. 
attendees and 234 (94.7\%) had internet access. Confidentiality was more important than face-to-face consultations or $24 \mathrm{hr}$ access to testing $(\mathrm{p}=0.036)$. Previous GUM attendees were more likely to book appointments compared to new users who would attend a drop-in clinic $(\mathrm{p}=0.011)$.

\begin{tabular}{|c|c|c|c|}
\hline & Yes $(\%)$ & No $(\%)$ & P-Value \\
\hline Car Access & 63.7 & 26.3 & \\
\hline$<18$ & 67.6 & 32.4 & 0.000 \\
\hline $18-25$ & 58.2 & 41.8 & \\
\hline$>25$ & 86.9 & 13.1 & \\
\hline Interested in Online Booking & 71.8 & 28.2 & \\
\hline$<18$ & 54.3 & 45.7 & 0.023 \\
\hline $18-25$ & 78.9 & 21.1 & \\
\hline$>25$ & 71.7 & 28.3 & \\
\hline Would take finger prick blood test (FPBT) & 71.7 & 28.3 & \\
\hline Men & 75.6 & 24.4 & 0.366 \\
\hline Women & 69.6 & 30.4 & \\
\hline$<18$ & 58.8 & 41.2 & 0.354 \\
\hline $18-25$ & 70.0 & 30.0 & \\
\hline$>25$ & 74.8 & 25.2 & \\
\hline Would take Chlamydia (CT) and & 86.3 & 13.7 & \\
\hline \multicolumn{4}{|l|}{ Gonorrhoea (GC) samples } \\
\hline Men & 90.0 & 10.0 & 0.237 \\
\hline Women & 83.8 & 16.2 & \\
\hline$<18$ & 73.3 & 26.7 & 0.060 \\
\hline $18-25$ & 92.2 & 7.8 & \\
\hline$>25$ & 83.5 & 16.5 & \\
\hline
\end{tabular}

Discussion/conclusion Patients would be willing to consider online services. Home testing could reach those who struggle to access clinics through lack of transport and appealed most to patients $>18$ years, a group that should be targeted.

\section{P098 ADHERENCE TO AND ACCEPTABILITY OF MOUTHWASH AS A POTENTIAL PREVENTIVE INTERVENTION FOR PHARYNGEAL GONORRHOEA AMONG MEN WHO HAVE SEX WITH MEN IN AUSTRALIA - AN OBSERVATIONAL STUDY}

\footnotetext{
1,2Vincent Cornelisse* ${ }^{1,2}$ Christopher Fairley, 1,2Sandra Walker, 1,2Tameka Young, ${ }^{1,2}$ David Lee, ${ }^{1,2}$ Marcus Chen, ${ }^{1,2}$ Catriona Bradshaw, ${ }^{1,2}$ Eric Chow. ${ }^{1}$ Melbourne Sexual Health Centre, Melbourne, Australia; ${ }^{2}$ Monash University, Melbourne, Australia
}

\subsection{6/sextrans-2016-052718.152}

Background/Introduction Gonorrhoea infections amongst men who have sex with men (MSM) are at a 20 -year high, and antibiotic resistance is also increasing. Pharyngeal gonorrhoea is an important contributor to gonorrhoea transmission, and gonorrhoea acquires genes that confer antibiotic resistance from other pharyngeal bacteria.

Aim(s)/Objective(s) This study assessed whether MSM would adhere to a regimen of daily mouthwash use, as a new intervention to prevent pharyngeal gonorrhoea.

Methods Ten MSM at were invited to use Listerine ${ }^{\circledR}$ alcoholcontaining mouthwash daily for 14 days in August 2015. Participants were asked to complete baseline and follow-up questionnaires about their experience of mouthwash use, and a daily diary to record mouthwash use over the 14-day study period.

Results The participants' mean age was 28 years (SD 7.2). Mouthwash was used at least once daily for 133 of 140 days (95\% of days; 95\% CI 90\% to 98\%). All ten men reported willingness to use mouthwash on a daily basis, and nine men were willing to use mouthwash after oral sex.

Conclusion:; This study showed a high adherence to daily use of mouthwash and that it is an acceptable intervention to reduce the risk of pharyngeal gonorrhoea in MSM. Further studies are required to assess whether Listerine ${ }^{\circledR}$ mouthwash is effective against pharyngeal gonorrhoea in vitro and in vivo. If this is confirmed, then this will be a novel strategy to reduce transmission of gonorrhoea amongst MSM and may potentially also reduce rates of antimicrobial resistance.

\section{P099 RENAL SAFETY OF TENOFOVIR ALAFENAMIDE IN PATIENTS AT HIGH RISK OF KIDNEY DISEASE}

${ }^{1}$ Laura Waters*, ${ }^{2}$ David Wohl, ${ }^{3}$ Anders Thalme, ${ }^{4}$ Robert Finlayson, ${ }^{5}$ Shinichi Oka, ${ }^{6}$ Moupali Das, ${ }^{7}$ Stuart Yau, ${ }^{6}$ Marshall Fordyce. ${ }^{1}$ Mortimer Market Centre, London, UK; ${ }^{2}$ University of North Carolina at Chapel Hill, North Carolina, USA; ${ }^{3}$ Karolinska University Hospital, Stockholm, Sweden; ${ }^{4}$ Taylor Square Private Clinic, NSW, Australia; ${ }^{5}$ National Centre for Global Health and Medicine Hospital, Tokyo, Japan; ${ }^{6}$ Gilead Sciences, Inc, Foster City, CA, USA; ${ }^{7}$ Gilead Sciences Ltd, High Holborn., London, UK

\subsection{6/sextrans-2016-052718.153}

Background/introduction Compared with tenofovir disoproxil fumarate (TDF), tenofovir alafenamide (TAF) results in significantly reduced plasma tenofovir (TFV) and has demonstrated less impact on surrogate markers of renal and bone health in multiple populations, but renal outcomes in treatment-naïve subjects at risk for chronic kidney disease (CKD) have not been characterised.

Aim(s)/objectives Renal outcomes in treatment-naïve subjects at risk for chronic kidney disease (CKD) were investigated.

Methods Treatment naïve HIV-1+ adults were randomised 1:1 to a single tablet regimen of elvitegravir, cobicistat, emtricitabine, with TAF $(\mathrm{E} / \mathrm{C} / \mathrm{F} / \mathrm{TAF})$ or $(\mathrm{E} / \mathrm{C} / \mathrm{F} / \mathrm{TDF})$ once daily in two double blind studies. Assessments of renal function including markers of proximal renal tubulopathy were carried out. A post-hoc analysis of renal function by group with high risk vs low risk for development of CKD is described.

Results Of 1,733 participants, those with high CKD risk was similar by treatment arm (E/C/F/TAF 28\%, E/C/F/TDF 32\%). Among high CKD risk participants, significantly fewer subjects on $\mathrm{E} / \mathrm{C} / \mathrm{F} / \mathrm{TAF}$ experienced a decline in eGFR to below $60 \mathrm{~mL} /$ min compared to $\mathrm{E} / \mathrm{C} / \mathrm{F} / \mathrm{TDF}: 4.9 \%$ vs $9.6 \%$ ( $\mathrm{p}=0.044$ ). Participants with high CKD risk who initiated $\mathrm{E} / \mathrm{C} / \mathrm{F} / \mathrm{TAF}$ also had significant declines in multiple measures of quantitative proteinuria. Within the low CKD risk group, significantly fewer participants receiving $\mathrm{E} / \mathrm{C} / \mathrm{F} / \mathrm{TAF}$ experienced a decline in eGFR by $\geq 25 \%$ $(11.5 \%$ vs $24.9 \%, p<0.001)$. High rates of virologic suppression at week 48 were observed in both treatment groups in the high CKD risk category.

Discussion/conclusion Among participants with both low and high CKD risk, participants receiving $\mathrm{E} / \mathrm{C} / \mathrm{F} / \mathrm{TAF}$ had more favourable renal outcomes compared with those treated with $\mathrm{E} /$ $\mathrm{C} / \mathrm{F} / \mathrm{TDF}$. These data support the improved renal safety profile of TAF. 